\title{
Fabrication of Superhydrophobic Nanocomposite Coatings Using Polytetrafluoroethylene and Silica Nanoparticles
}

\author{
Bharathibai J. Basu and V. Dinesh Kumar \\ Surface Engineering Division, CSIR National Aerospace Laboratories, Bangalore 560017, India \\ Correspondence should be addressed to Bharathibai J. Basu, bharathi@nal.res.in
}

Received 18 April 2011; Accepted 12 May 2011

Academic Editors: J.-I. Shirakashi and D. Wang

Copyright $\odot 2011$ B. J. Basu and V. Dinesh Kumar. This is an open access article distributed under the Creative Commons Attribution License, which permits unrestricted use, distribution, and reproduction in any medium, provided the original work is properly cited.

\begin{abstract}
Superhydrophobic nanocomposite coatings were fabricated by incorporating hydrophobically modified silica (HMS) nanoparticles in polytetrafluoroethylene (PTFE) emulsion. Hydrophobicity of the coating was dependent on the concentration of HMS. Coatings containing optimum amounts of PTFE and HMS exhibited superhydrophobic property with high water contact angle (WCA) of $165^{\circ}$ and low sliding angle $<2^{\circ}$. Scanning electron microscopic (SEM) studies have shown a binary surface topography composed of microbumps and nanoscale granules. The synergistic effect of the micro-nano-binary structure and low surface energy of PTFE was responsible for the superhydrophobicity of the coating. The method is simple and cost-effective and can be used for preparing self-cleaning superhydrophobic coatings on large areas of different kinds of substrates like glass, metal, and composites.
\end{abstract}

\section{Introduction}

Superhydrophobic (SH) surfaces have attracted a lot of attention because of their unique properties such as self-cleaning, antisticking, and anticontamination [1-10]. Although research on water-repellent surfaces began many decades ago, it was only recently a lot of papers on superhydrophobicity appeared in the literature especially after the micro-nano-binary microstructure of lotus leaf was studied [5]. Some of the recent reviews describe the rapid progress in the preparation of $\mathrm{SH}$ surfaces and their functional applications and also on the theory relating roughness and wettability [1-4]. The hydrophobicity of solid surfaces is influenced both by the presence of binary geometric structures at micronanometer scales and the chemical composition [6]. Therefore, SH surfaces can be prepared either by creating roughness on the surface of low surface energy materials or by lowering the surface energy of a rough material.

Fluorinated polymers are of special interest in the creation of superhydrophobic surfaces due to their extremely low surface energies [7-20]. Among the fluorocarbons, polytetrafluoroethylene (PTFE) is widely used as coatings for antiadhesion agents and chemical insulators because of its very low surface energy. However, many fluorinated materials have not been used directly because of their limited solubility but linked or blended with other materials to make SH surfaces. Roughening these polymers in different ways leads to superhydrophobicity directly. For example, Peng et al. have obtained a highly hydrophobic porous polyvinylidene fluoride (PVDF) by using a modified phase inversion method [7]. PTFE surfaces show hydrophobic and oleophobic characteristics. The hydrophobic properties of PTFE are caused by the fluorination of the carbon bonds. Water contact angles (WCAs) on smooth PTFE are found to be about 100 to $110^{\circ}$. The hydrophobic properties of PTFE are caused by the fluorination of the carbon bonds. Unfortunately, PTFE is difficult to handle because of its insolubility, viscosity, and melt strength.

Several different approaches were tried to prepare superhydrophobic PTFE surfaces [8-15]. Zhang et al. have reported a simple way to achieve an $\mathrm{SH}$ film by stretching a PTFE film [8]. The extended film consisted of fibrous crystals with a large fraction of void space in the surface which was believed responsible for the superhydrophobicity. Recently, SH surface has been created using PEEK/PTFE 
composite coating and the topographical microstructures are controlled by adjusting the curing temperature [9]. The microstructure is controlled by curing temperature, and superhydrophobic surface is obtained when the coating is cured at $300^{\circ} \mathrm{C}$. The surface consisted of fibrous crystals with a large fraction of void space. SH surface with WCA of $167^{\circ}$ was obtained by electrospraying of an aqueous suspension containing $60 \%$ PTFE with particles ranging from 0.05 to $0.5 \mu \mathrm{m}$ on FTO-doped glass [10]. SEM shows the typical rough micro-/nanostructure required for $\mathrm{SH}$. Heat treatment and deposition time were critical factors to attain superhydrophobicity. Lau et al. obtained CNT forest coated with PTFE using a hot filament CVD process which has shown high WCA [11]. Minko et al. have reported oxygen plasma treatment of PTFE for the fabrication of $\mathrm{SH}$ surfaces with WCA of about $160^{\circ}$ without CA hysteresis [12]. Fluorocarbon coatings have also been deposited by RF plasma treatments [13-16]. Sarkar et al. have shown that the presence of $-\mathrm{CF}_{3}$ radicals along with $-\mathrm{CF}_{2}$ radicals in the ultrathin rf-sputtered Teflon films contributed to the lowering of the surface energy on the $\mathrm{SH}$ aluminum surfaces [14].

A simple method to prepare $\mathrm{SH}$ surface is by introducing roughness to a hydrophobic surface with WCA $>90^{\circ}$. In many of the reported methods for the preparation of $\mathrm{SH}$ coatings, fluoroalkylsilanes are either incorporated in the coating or applied as a topcoat in order to decrease the surface energy [17-19]. Nanosilica particles have been employed to create roughness on different substrates, and superhydrophobicity was achieved by subsequent fluoroalkylsilane coating $[17,18]$. SH properties of polymerbased nanocomposite coatings prepared by dispersing nano$\mathrm{CaCO}_{3}$ in PVDF have been reported [19]. Our previous studies have shown that polyvinylidene difluoride (PVDF) or sol-gel can be used as a binder matrix to prepare composite coatings with SH property [20,21]. Even though PTFE has lower surface energy than PVDF, it is difficult to prepare coatings with it due to its low adhesion to surfaces and limited solubility in solvents.

In the present work, PTFE-based nanocomposite coatings were prepared by incorporating HMS nanoparticles in PTFE emulsion. The concentrations of PTFE and HMS were optimised to achieve superhydrophobic property. Spray coating was selected for applying the coating because of its advantages for preparing coatings of desired thickness with minimum wastage of solution. Therefore, it is a facile approach for creating superhydrophobic and self-cleaning surfaces.

\section{Experimental}

Commercial grade PTFE emulsion, Nimuflon F, was purchased from Grauer and Weil, India. Hydrophobically modified silica (HMS) was procured from M/s ABCR GmbH, Germany. These particles are highly hydrophobic in nature as they are treated with hexamethyldisilazane (HMDS) and have particle size of 0.02 micron (as per the specifications given in the Gelest catalog).
Dimethylformamide (DMF) and toluene were purchased from Sigma Aldrich. PTFE solution $(20 \mathrm{wt} \%)$ was prepared by mixing $2.0 \mathrm{~g}$ PTFE emulsion in $10 \mathrm{~mL}$ DMF to get a homogeneous solution. To prepare PTFE-HMS composite coating, a known amount of HMS silica was dispersed in DMF by ultrasonication for $15 \mathrm{~min}$, mixed with $2.5 \mathrm{~mL}$ PTFE solution, and magnetically stirred for $1 \mathrm{~h}$ till a homogenous mixture was obtained. The mixture was transferred to a spray gun and sprayed on to clean dry glass slides or aluminium coupons or other substrates using compressed air pressure of $20 \pm 5$ psi. Spraying was done in a number of passes until the surface was covered with a film of uniform thickness. The coating was dried at room temperature for $24 \mathrm{~h}$ and heated at $100^{\circ} \mathrm{C}$ for $1 \mathrm{~h}$ to expel trapped solvents. For comparison, a smooth PTFE film was prepared by solution casting PTFE solution on a glass slide.

WCA values of the films were measured by sessile drop method using a Contact Angle Analyzer model Phoenix 300 Plus from M/s Surface Electro Optics, South Korea. Tangent fitting mode was used in this instrument to determine CA values. The water droplet used for measurements was $8 \mu \mathrm{L}$. Five measurements at five locations on the film surface were taken, and the mean value was reported. The uncertainty in measurements of WCA was about $\pm 2^{\circ}$. The contact angle hysteresis (CAH) of the films was obtained by dynamic CA measurements, as the difference between advancing contact angle and receding contact angle. Sliding angle (SA) measurements were made using a simple instrument fabricated in our laboratory which consisted of a smooth and planar platform on which the sample was fixed. The angle at which the drop slides can be measured by means of a protractor attached to the instrument. The maximum SA that can be measured using this instrument was $90^{\circ}$. MilliQ water was used for WCA and SA measurements. Surface morphology of the composite coatings was examined using LEO 440I scanning electron microscope. Surface roughness of the coatings was measured by a roughness profilometer, model Talysurf Intra from Taylor Hobson. Thickness of the films was measured using Digimatic Micrometer, model Mitutoyo 293-805, and was found to be in the range of 10 to $15 \mu \mathrm{m}$.

\section{Results and Discussion}

HMS is hydrophobically modified nanosilica in which the surface hydroxyl groups are replaced by methyl groups by treatment with hexamethyldisilazane. Figure 1 shows the FESEM image of a dispersion of HMS in which the size of individual nanoparticles was seen to be in the range of 20 to $30 \mathrm{~nm}$.

WCA of a smooth PTFE film was about $110^{\circ}$ which indicates the hydrophobic nature of PTFE. The weight $\%$ of PTFE solid in PTFE emulsion was determined by heating $1.0 \mathrm{~g}$ PTFE emulsion at $100^{\circ} \mathrm{C}$ till constant weight was obtained. It was found that PTFE emulsion contains 67\% solid. For calculation of the weight \% of HMS nanosilica in PTFE-HMS composite coating, the weight of solid PTFE in the coating was used. The effect of the concentration of HMS 


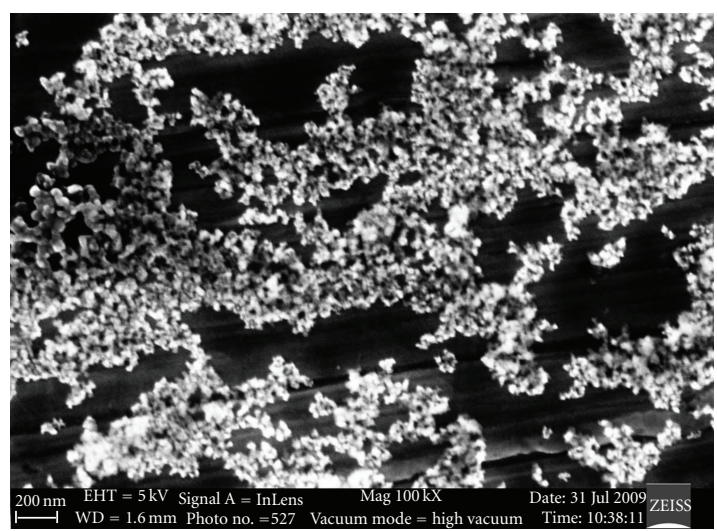

Figure 1: FESEM image of ultrasonicated HMS nanoparticles; magnification, $100 \mathrm{kX}$.

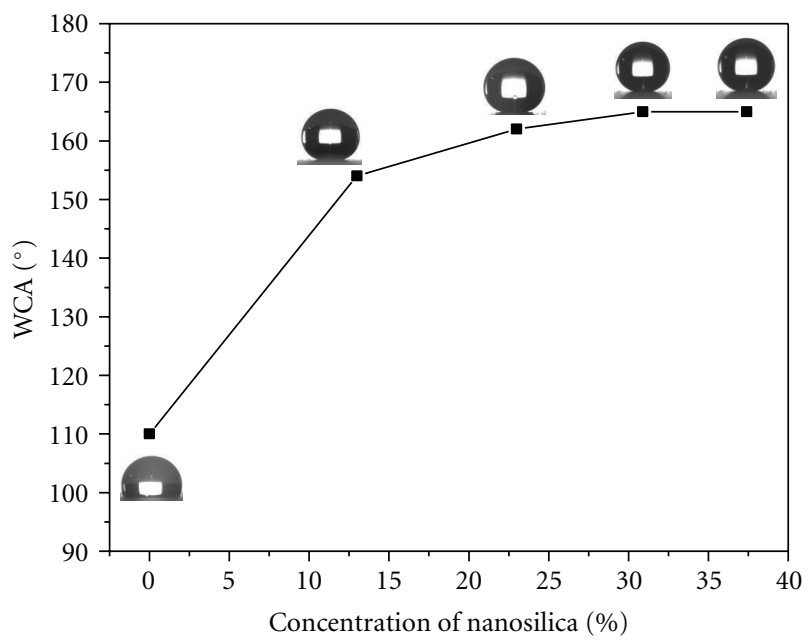

FIGURE 2: Effect of the concentration of HMS nanosilica on WCA of PTFE-HMS nanocomposite coatings. Insets show images of water drop on the films.

nanosilica on the hydrophobicity of PTFE-HMS composite coating was studied. The results are shown in Figure 2. It was found that WCA increased with increase in concentration of HMS nanoparticles in the coating. Superhydrophobic property with WCA $>150^{\circ}$ was obtained at HMS concentrations $\geq 13 \%$. When HMS concentration was $\geq 23 \%$, WCA increased $160^{\circ}$ and SA decreased to $<5^{\circ}$ so that water drops rolled off the surface. Maximum superhydrophobicity with a WCA of $165^{\circ}$ and SA of $<2^{\circ}$ was achieved at HMS concentrations $>30 \%$. The insets in Figure 2 show images of water droplet on PTFE-HMS composite coatings with different nanosilica concentrations.

The surface morphology of PTFE-HMS composite coating was examined by using scanning electron microscopy (SEM). Figure 3 shows SEM images of the composite coatings with two different HMS concentrations. It can be seen that the coatings were free from cracks and had a lotusleaf-like microstructure with microscale bumps and clusters. These may be aggregates of HMS nanoparticles. SEM images at higher magnification exhibited tiny particles of 50 to $200 \mathrm{~nm}$ size and also pores of similar size. Similar aggregates of spherical particles have been reported earlier in the case of electrosprayed PTFE coatings [10]. At higher HMS concentrations (37\%), the spherical particles appeared to be merged together but pores of 50 to $100 \mathrm{~nm}$ were present. Thus the surface morphology showed a dual micro-nanostructure. Hsieh et al. have proposed that water droplets cannot penetrate easily into micropores on a repellent surface, and therefore, rough surfaces with a high fraction of micropores enhance superhydrophobicity [22]. This is found to be true in the case of PTFE-HMS nanocomposite coatings.

The surface roughness profiles of two PTFE-HMS coatings with nearly same thickness of $10 \mu \mathrm{m}$ and HMS silica concentrations of $23 \%$ and $37 \%$ are shown in Figure 4 . The average roughness $\left(R_{a}\right)$ values for both coatings were in the same range, $0.69 \mu \mathrm{m}$ for the coating with $23 \%$ silica and $0.65 \mu \mathrm{m}$ for the coating with $37 \%$ silica. Thus it was found that surface roughness was not much influenced by silica concentration. However, $R_{a}$ values for thicker coatings $(20 \mu \mathrm{m})$ were found to be higher.

The surface microstructures of PTFE-HMS coatings were rough with pores and clusters of nanoparticles. On such a binary micro-nano rough structure, water drops were suspended with trapped air between water and the rough microstructure which is the composite state according to Cassie's model [23]. The apparent CA $\left(\theta^{c}\right)$ of a drop on a rough surface is given by Cassie's equation

$$
\cos \theta^{c}=f_{1}\left(\cos \theta_{e}+1\right)-1,
$$

where $f_{1}$ is the surface area fraction of the solid and $\theta_{e}$ is the equilibrium CA. PTFE is a hydrophobic material, and a flat smooth film shows a WCA $\left(\theta_{e}\right)$ of about $110^{\circ}$. The surface area fraction of the solid, $f_{1}$, was calculated using (1) by substituting for $\theta_{e}=110^{\circ}$ and $\theta^{c}=165^{\circ}$ and found to be 0.052 . This low value of $f_{1}$ indicates that a lot of air is trapped under the water drop. Thus the coatings exhibited superhydrophobicity due to the combined effect of micronanostructure and the low surface energy of PTFE and HMS particles. The large number of methyl groups on the surface of HMS particles lowered the surface energy.

The usefulness of a superhydrophobic coating is determined by its stability. The PTFE-HMS coatings had good stability when stored under ambient conditions. WCA and SA remained unchanged even after several months. Further, a simple water immersion test was carried out to assess the stability of SH property of the PTFE-HMS composite coating. A minimum requirement for the usefulness of an $\mathrm{SH}$ coating is that the surface should retain its water repellent properties on contact with the medium itself. Zimmerman et al. have reported the effect of water immersion on WCA and SA of SH surfaces made of silicone nanofilaments [24]. Therefore, the coatings were immersed in milli-Q water, taken out periodically at regular intervals, dried at room temperature for $1 \mathrm{~h}$, and WCA and SA were measured. The results are shown in Figure 5 for the coating containing $37 \%$ HMS silica. It was found that the composite coating retained superhydrophobicity even after immersion in water 


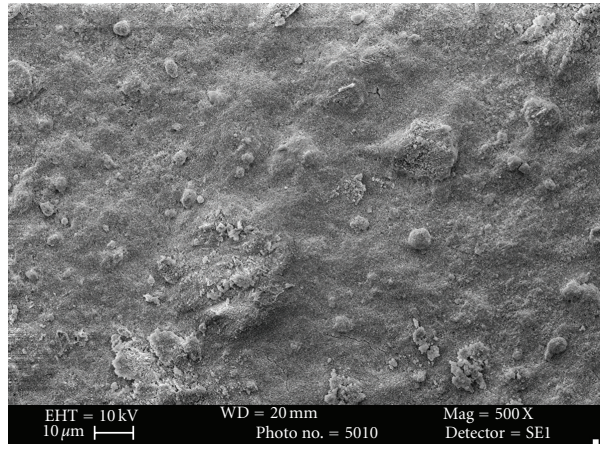

(a)

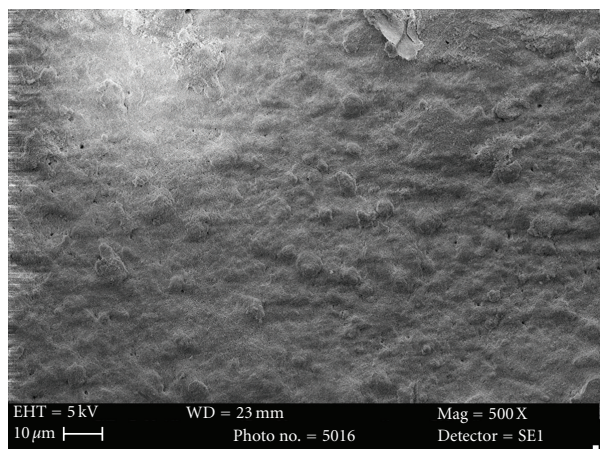

(c)

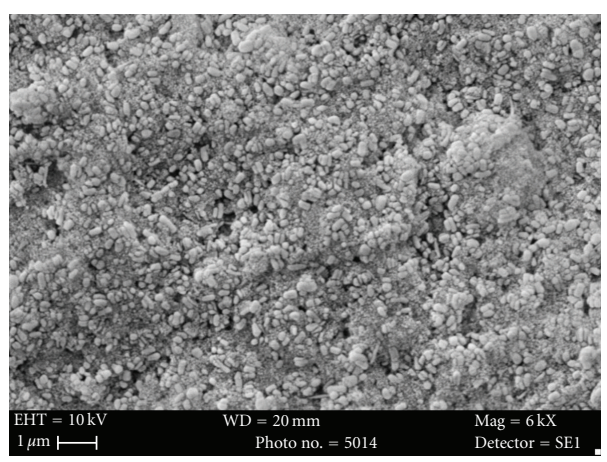

(b)

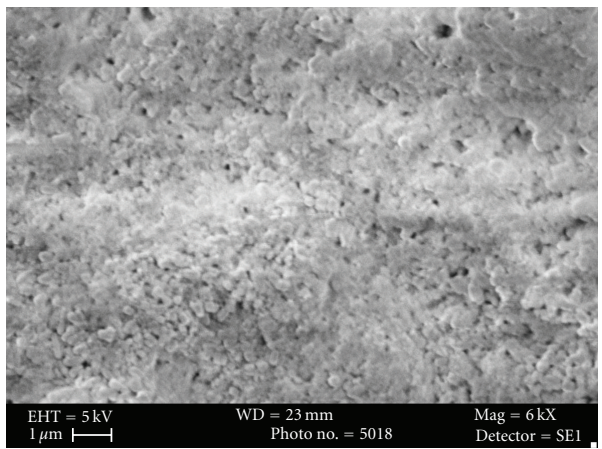

(d)

FIgURE 3: SEM images of PTFE-HMS nanocomposite coatings containing different concentrations of nanosilica; (a) and (b) 23\%, (c) and (d) 37\%; magnifications (a) and (c) $500 \mathrm{X}$; (b) and (d) $6.0 \mathrm{kX}$.

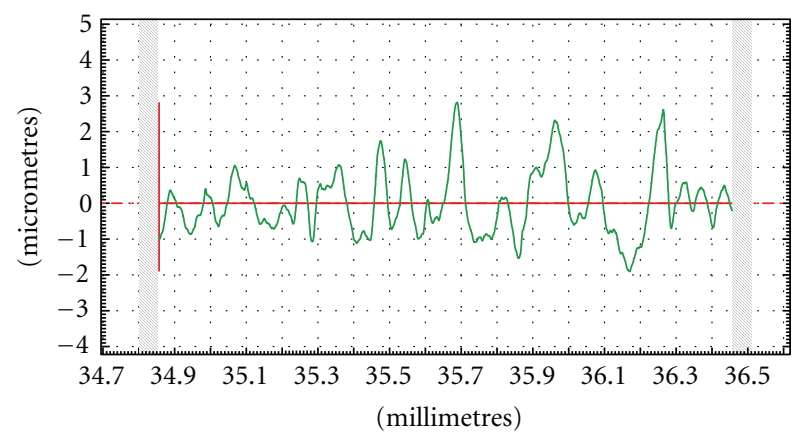

(a)

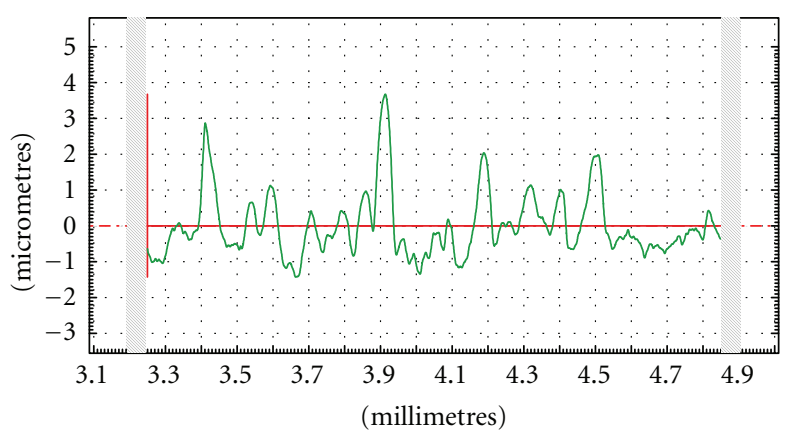

(b)

FIgURE 4: Surface roughness profiles of PTFE-HMS coatings with (a) 23\% and (b) 37\% HMS nanosilica.

for about $100 \mathrm{~h}$. WCA of the film remained $>150^{\circ}$ but an increase in SA from $1^{\circ}$ to $18^{\circ}$ was observed after $100 \mathrm{~h}$ of immersion. Therefore, a slight tilting of the surface was needed for the water drops to roll. The increase in sliding angle may be due to surface defects and inhomogeneities. It is presumed that hydrophilic defects on the surface are generated during immersion that lead to an increase in SA without influencing the static contact angle [24]. The coating regained the $\mathrm{SH}$ property after drying at room temperature. This high stability of water repellency can be attributed not only to the rough porous microstructure but also to the low surface energy of hydrophobic silica and PTFE. Water could not penetrate into the air gaps in the micropores and crevices on the rough surface of the coating. It was also found that coatings with higher HMS concentration (31\% and 37\%) showed better water immersion stability than coatings with lower HMS content (13\% and 23\%).

The effect of thermal treatment on the wettability of the PTFE-HMS coating containing 37\% HMS nanosilica was studied. The films were heated at different temperatures, 100, $150,200,250,300$, and $350^{\circ} \mathrm{C}$ for $1 \mathrm{~h}$, and WCA values were measured at room temperature after each heat treatment. The results are shown in Figure 6. It was found that the coating retained $\mathrm{SH}$ property after heating up to $300^{\circ} \mathrm{C}$ and 


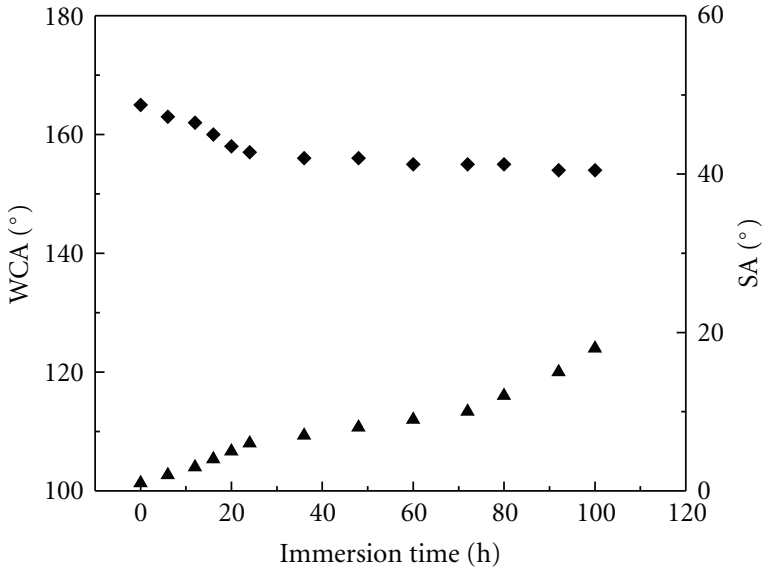

- WCA

- SA

FIgURE 5: Effect of water immersion time on WCA and SA of the PTFE-HMS nanocomposite coating.

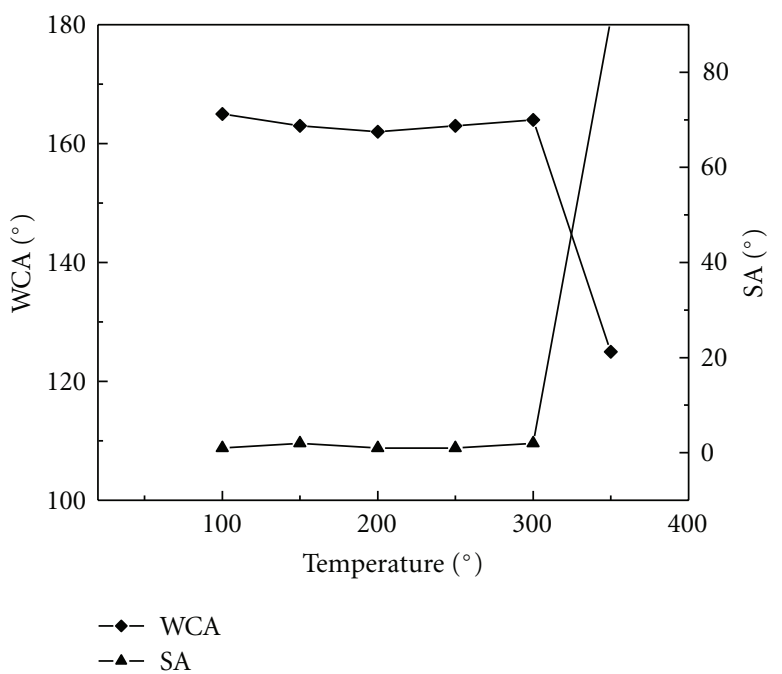

Figure 6: Effect of heat treatment on WCA and SA of the PTFEHMS nanocomposite coating.

water drops rolled on the surface of the coating. However, after heat treatment at $350^{\circ} \mathrm{C}$ for $1 \mathrm{~h}$, WCA decreased to $125^{\circ}$ and SA increased to $>90^{\circ}$, and water drops wetted the coating surface. Thus superhydrophobic PTFE-HMS coatings displayed good thermal stability up to $300^{\circ} \mathrm{C}$.

\section{Conclusions}

A facile approach for the fabrication of superhydrophobic coating by incorporating hydrophobically modified silica particles in PTFE matrix is described. The synergistic effect of the presence of micro-nano-binary microstructure as revealed by scanning electron microscopy (SEM) together with the low surface energy of PTFE renders the nanocomposite coatings highly superhydrophobic. The method is simple and cost-effective and can be used for preparing selfcleaning superhydrophobic coating on large areas of different kinds of substrates for practical applications.

\section{Acknowledgments}

The authors are grateful to Dr. A. R. Upadhya, Director, NAL, Bangalore and Dr. K. S. Rajam, Head, Surface Engineering Division, NAL for their constant support and encouragement for this work. They thank Mr. K. Raghavendra, NAL for SEM studies. They greatly appreciate the funding assistance provided by CSIR for carrying out the studies.

\section{References}

[1] X.-M. Li, D. Reinhoudt, and M. Crego-Calama, "What do we need for a superhydrophobic surface? A review on the recent progress in the preparation of superhydrophobic surfaces," Chemical Society Reviews, vol. 36, no. 8, pp. 1350-1368, 2007.

[2] X. Zhang, F. Shi, J. Niu, Y. Jiang, and Z. Wang, "Superhydrophobic surfaces: from structural control to functional application," Journal of Materials Chemistry, vol. 18, no. 6, pp. 621-633, 2008.

[3] M. Ma and R. M. Hill, "Superhydrophobic surfaces," Current Opinion in Colloid and Interface Science, vol. 11, no. 4, pp. 193202, 2006.

[4] P. Roach, N. J. Shirtcliffe, and M. I. Newton, "Progess in superhydrophobic surface development," Soft Matter, vol. 4, no. 2, pp. 224-240, 2008.

[5] W. Barthlott and C. Neinhuis, "Purity of the sacred lotus, or escape from contamination in biological surfaces," Planta, vol. 202, no. 1, pp. 1-8, 1997.

[6] N. A. Patankar, "Mimicking the lotus effect: influence of double roughness structures and slender pillars," Langmuir, vol. 20, no. 19, pp. 8209-8213, 2004.

[7] M. Peng, H. Li, L. Wu, Q. Zheng, Y. Chen, and W. Gu, "Porous poly(vinylidene fluoride) membrane with highly hydrophobic surface," Journal of Applied Polymer Science, vol. 98, no. 3, pp. 1358-1363, 2005.

[8] J. L. Zhang, J. A. Li, Y. Fan, and Y. C. Han, "Fabricating superhydrophobie lotus-leaf-like surfaces through soft-lithographic imprinting," Macromolecular Rapid Communications, vol. 25, pp. 1105-1108, 2004.

[9] H.-J. Song, Z.-Z. Zhang, and X.-H. Men, "Superhydrophobic PEEK/PTFE composite coating," Applied Physics A, vol. 91, no. 1, pp. 73-76, 2008.

[10] E. Burkarter, C. K. Saul, F. Thomazi, N. C. Cruz, L. S. Roman, and W. H. Schreiner, "Superhydrophobic electrosprayed PTFE," Surface and Coatings Technology, vol. 202, no. 1, pp. 194-198, 2007.

[11] K. K. S. Lau, J. Bico, K. B. K. Teo et al., "Superhydrophobic carbon nanotube forests," Nano Letters, vol. 3, no. 12, pp. 1701-1705, 2003.

[12] S. Minko, M. Müller, M. Motornov, M. Nitschke, K. Grundke, and M. Stamm, "Two-level structured self-adaptive surfaces with reversibly tunable properties," Journal of the American Chemical Society, vol. 125, no. 13, pp. 3896-3900, 2003.

[13] S. H. Kim, J. H. Kim, B. K. Kang, and H. S. Uhm, "Superhydrophobic $\mathrm{CF}_{x}$ coating via in-line atmospheric RF plasma of $\mathrm{He}-\mathrm{CF}_{4}-\mathrm{H}_{2}$," Langmuir, vol. 21, no. 26, pp. 12213-12217, 2005. 
[14] D. K. Sarkar, M. Farzaneh, and R. W. Paynter, "Superhydrophobic properties of ultrathin rf-sputtered Teflon films coated etched aluminum surfaces," Materials Letters, vol. 62, no. 8-9, pp. 1226-1229, 2008.

[15] P. Favia, G. Cicala, A. Milella, F. Palumbo, P. Rossini, and R. d'Agostino, "Deposition of super-hydrophobic fluorocarbon coatings in modulated RF glow discharges," Surface and Coatings Technology, vol. 169-170, pp. 609-612, 2003.

[16] V. Stelmashuk, H. Biederman, D. Slavínská, J. Zemek, and M. Trchová, "Plasma polymer films rf sputtered from PTFE under various argon pressures," Vacuum, vol. 77, no. 2, pp. 131-137, 2005.

[17] C. Su, J. Li, H. Geng, Q. Wang, and Q. Chen, "Fabrication of an optically transparent super-hydrophobic surface via embedding nano-silica," Applied Surface Science, vol. 253, no. 5, pp. 2633-2636, 2006.

[18] M. Hikita, K. Tanaka, T. Nakamura, T. Kajiyama, and A. Takahara, "Super-liquid-repellent surfaces prepared by colloidal silica nanoparticles covered with fluoroalkyl groups," Langmuir, vol. 21, no. 16, pp. 7299-7302, 2005.

[19] L. Yan, K. Wang, and L. Ye, "Super hydrophobic property of $\mathrm{PVDF} / \mathrm{CaCO}_{3}$ nanocomposite coatings," Journal of Materials Science Letters, vol. 22, no. 23, pp. 1713-1717, 2003.

[20] B. J. Basu and A. K. Paranthaman, "A simple method for the preparation of superhydrophobic PVDF-HMFS hybrid composite coatings," Applied Surface Science, vol. 255, no. 8, pp. 4479-4483, 2009.

[21] B. J. Basu, V. Hariprakash, S. T. Aruna, R. V. Lakshmi, J. Manasa, and B. S. Shruthi, "Effect of microstructure and surface roughness on the wettability of superhydrophobic solgel nanocomposite coatings," Journal of Sol-Gel Science and Technology, vol. 56, no. 3, pp. 278-286, 2010.

[22] C. T. Hsieh, J. M. Chen, R. R. Kuo, T. S. Lin, and C. F. Wu, "Influence of surface roughness on water- and oil-repellent surfaces coated with nanoparticles," Applied Surface Science, vol. 240, no. 1-4, pp. 318-326, 2005.

[23] A. B. D. Cassie and S. Baxter, "Wettability of porous surfaces," Transactions of the Faraday Society, vol. 40, pp. 546-551, 1944.

[24] J. Zimmermann, G. R. J. Artus, and S. Seeger, "Long term studies on the chemical stability of a superhydrophobic silicone nanofilament coating," Applied Surface Science, vol. 253, no. 14, pp. 5972-5979, 2007. 

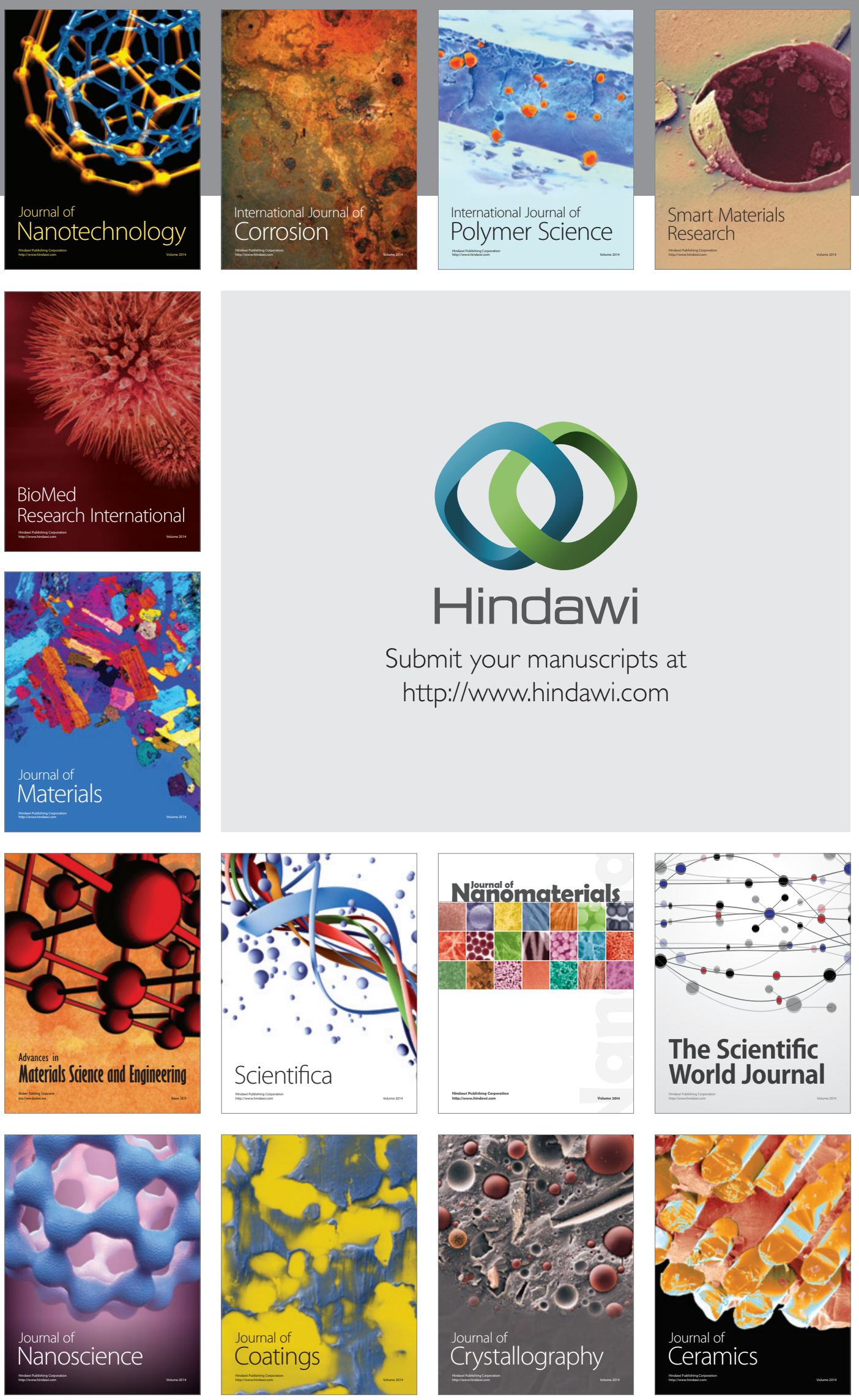

The Scientific World Journal

Submit your manuscripts at

http://www.hindawi.com

\section{World Journal}

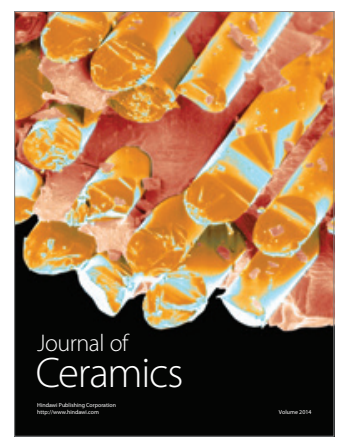

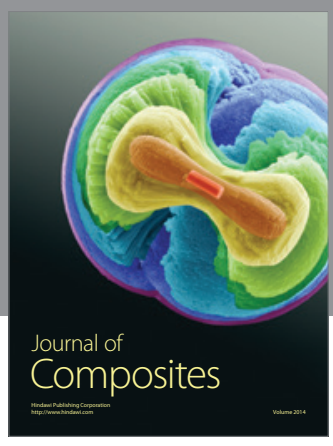
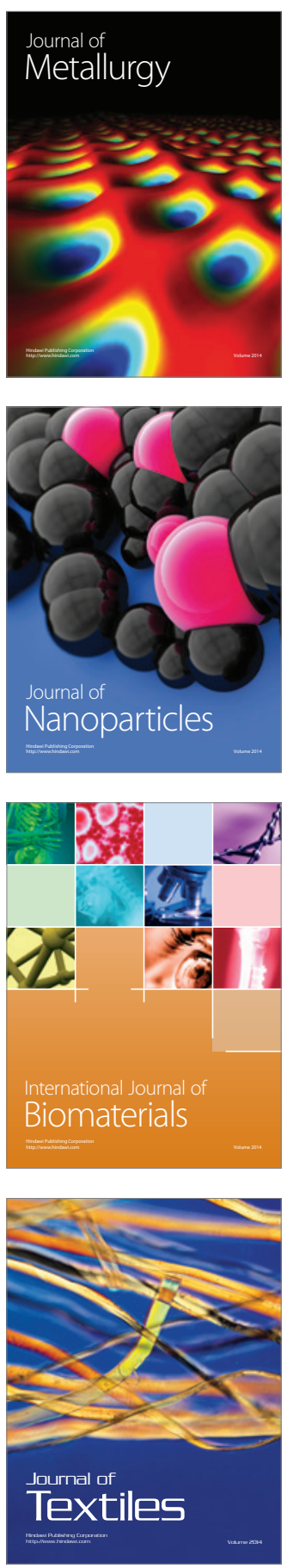